\title{
Yielding Accuracy of Morning and Spot Sputum Samples for Diagnosis Mycobacterium Tuberculosis Using Gene Xpert MTB/RIF Assay at EPHI, Addis Ababa, Ethiopia
}

\author{
Habtamu Molla* \\ Clinical Laboratory Science, College of Health Sciences, Addis Ababa University, Addis Ababa-1000, Ethiopia \\ *Email: habtamumolla8@gmail.com
}

\section{ARTICLE INFORMATION}

Received: April 02, 2019

Revised: June 09, 2020

Accepted: June 20, 2020

Published Online: July 17, 2020

\section{Keywords:}

Gene, MTB, RIF, Xpert,

Smear negative TB

\section{ABSTRACT}

Background: Tuberculosis is a global health problem and leading cause of mortality and morbidity in the world. Correct diagnosis of tuberculosis is the main challenge for control of tuberculosis. World health organization has prioritized improving diagnostic guidelines and tests for TB diagnosis. Priority has been given for development of new Tuberculosis diagnostic methods. But diagnosis of Tuberculosis highly affected by quality specimen collected which has been given less attention. The aim of this is to assess Yielding accuracy of morning and spot sputum samples for diagnosis Mycobacterium tuberculosis using Gene Xpert Mycobacterium Tuberculosis (MTB)/ Rifampicin Resistance (RIF).

Methodology: Cross sectional study was conducted and convenient sampling technique used to select participants. Checklists used to collect the data from April 1 to May 30, 2018 G.C. A total of two hundred twenty two (222) sputum samples from 111 suspected tuberculosis patients were analyzed using Gene Xpert MTB/RIF Assay. SPSS version 20 was used for statistical analysis.

Results: From 111 TB suspected patients, $55.9 \%$ were male and the rest of $44.1 \%$ was female. In terms of sample quality, $81.1 \%$ morning sputum samples and $79.3 \%$ spot sputum samples were had good sample quality. The outcomes of the research show an increase in odds value in sputum quality and sputum consistency for TB diagnosis. But, the relation is not significant association with TB positivity.

Conclusion: Based on the results of this study, the diagnosis of TB using spot sputum samples as well as using morning sputum samples is almost similar for detection of MTB by Gene Xpert MTB/RIF Assay. Physical Quality of sputum sample or consistency is not association with TB positivity using Gene Xpert MTB/RIF Assay.

\section{Introduction}

Per year around 10.4 million people are affected globally by tuberculosis infection. Among these around 1.4 million are dead, with pulmonary type of TB is the main cause. The main challenge for global tuberculosis control is accurate and correct diagnosis of tuberculosis. World health organization has prioritized improving tuberculosis diagnosis guidelines and testing procedures. But the accuracy of laboratory diagnostic procedures affected by quality of sputum sample collection and processing. Nowadays the impact of quality sputum sample has been given less concern rather priority given for development of new TB diagnostic methods (Jochei \& Akolhatkar, 1982; Charles et al., 2000). Most frequently used for laboratory diagnosis of TB is microscopy, which is inexpensive. But microscopy is less sensitive when the amount of acid fast bacilli low (most likely below 10,000 per $\mathrm{ml}$ not detected). Culture techniques for tuberculosis diagnosis have higher sensitivity than microscopic TB diagnosis. Gene Xpert MTB/RIF Assay has moderate sensitivity between culture techniques and microscopy. But Gene Xpert and culture techniques are more expensive than microscopy and only diagnosis when the amount of acid fast bacilli concentration is sufficient on the sputum sample (FMOH, 2012; Chemhuru et al., 2010; FMOH, 2014).

Inappropriate or poor quality sputum samples lead to false laboratory results for diagnosis of tuberculosis. Mostly poor sputum samples contain secretions from respiratory track with different amount saliva. The positivity of 
laboratory diagnosis of TB varies among different sputum samples from the same patient. For this reason more than one sputum sample is tested for suspected TB patients (Ethiopian Public Health Institute, the 2nd BSC Based EPHI's Strategic Management Plan, 2015/16 to 2019/20; FMOH, 2014; Daniel, 2014; Minaleshewa et al., 2016).

Spot-morning-spot sputum samples collection methods were used for TB microscopy. Recommended sputum sample collection methods are different in different and their relative advantage for tuberculosis diagnosis is not well explained. Using spot sputum samples reduces possible transmission of tuberculosis. This study has been done to assess yielding of spot and morning sputum samples for tuberculosis diagnosis using Gene Xpert MTB/RIF Assay and possible effect of sputum sample quality on TB diagnosis.

\section{Methodoloy}

\subsection{Study Area}

This study was conducted at Ethiopian Public Health Institute. It is located at Addis Ababa, capital city of Ethiopia. The institute is the center of health related researches, trainings and quality control of health service in Ethiopia.

\subsection{Study Period and Study Design}

Descriptive cross sectional study design was used to collect the data at Ethiopian Public Health Institute from April 1 to May 30, 2018 G.C.

\subsection{Population}

\subsubsection{Source population}

All TB suspected patients living in Addis Ababa city and around the city were source population for the study.

\subsubsection{Study population}

All TB suspected patients requested to Ethiopian Public Health Institute TB national reference laboratory section during the study period.

\subsection{Sample size and sampling technique}

A total of two hundred twenty two (222) morning and spot sputum specimens from one hundred eleven (111) individual were analyzed using Gene Xpert MTB/RIF Assay. All suspected TB patients who came to EPHI for TB diagnosis during the study period were included.

\subsection{Study Variables}

- Dependent variables: Presence of Mycobacterium Tuberculosis

- Independent variables: Age, Sex, Patient preparation, Sputum quality, Sputum consistency

\subsection{Data Collection Procedure}

Data was collected directly from M.TB suspected individuals by research participants and tested by Gene Xpert machine using both morning and spot sputum specimen.

The sample was collected by clean, leak-proof and wide mouthed falcon tube about 2-4 ml of each morning and spot specimen. Gene Xpert MTB/RIF Assay used for testing the samples. If delay was unavoidable in testing, refrigeration $2-8^{\circ} \mathrm{C}$ was used to store the specimen.

The whole process of patient preparation, specimen collection and testing were based on standard operating procedures manual. Mucoid and purulent sputum sample consider as good quality.

\subsection{Data Processing and Analysis}

The data was recorded, controlled and checked for its completeness everyday during the data collection period. All data was entered into an excel spreadsheet, and then transferred to SPSS version 20 for analysis. Descriptive statistics were performed and presented in tables and graph. Adjusted odds ratio and $\mathrm{p}$ value were used to assess relation of TB detection with sputum quality and consistency.

\subsection{Ethical Consideration}

Ethical clearance to do this research was obtained from Department of Medical Laboratory Science, Addis Ababa University. Written consent forms were agreed with patients to conduct the research.

\section{Results}

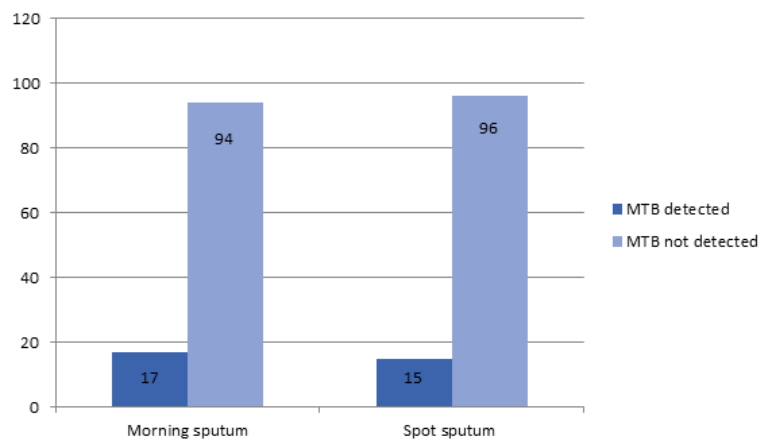

Figure 1: Distribution of MTB detection for both morning and spot sputum samples. 
Table 1: Age and Sex distribution of study participants.

\begin{tabular}{|l|l|}
\hline Variables & Number $(\%)$ \\
\hline Gender & \\
Male & $62(55.9)$ \\
Female & $49(44.1)$ \\
Total & $111(100.0)$ \\
\hline Age group & \\
$0-14$ years & $3(2.7)$ \\
$15-44$ years & $63(56.8)$ \\
$45-64$ years & $33(29.7)$ \\
$>65$ years & $12(10.8)$ \\
Total & $111(100.0)$ \\
\hline
\end{tabular}

Table 2: Sputum sample quality and consistency in both morning and spot collection methods.

\begin{tabular}{|c|c|c|c|c|c|}
\hline \multicolumn{2}{|c|}{ Variables Number } & \multicolumn{2}{c|}{ Morning sample } & \multicolumn{2}{c|}{ Spot sample } \\
\cline { 3 - 6 } & Percent & Number & Percent & Number \\
\hline \multirow{4}{*}{$\begin{array}{c}\text { Sputum } \\
\text { quality }\end{array}$} & $\begin{array}{c}\text { Good } \\
\text { quality }\end{array}$ & 90 & $81.1 \%$ & 88 & $79.3 \%$ \\
\cline { 2 - 6 } & $\begin{array}{c}\text { Poor } \\
\text { quality }\end{array}$ & 21 & $18.9 \%$ & 23 & $20.7 \%$ \\
\cline { 2 - 6 } & Total & 111 & $100.0 \%$ & 111 & $100.0 \%$ \\
\hline \multirow{4}{*}{$\begin{array}{c}\text { Sputum } \\
\text { consistency }\end{array}$} & Mucoid & 74 & 66.7 & 65 & 58.6 \\
\cline { 2 - 6 } & Purulent & 16 & 14.4 & 20 & 18.0 \\
\cline { 2 - 6 } & Saliva & 18 & 16.2 & 22 & 19.8 \\
\cline { 2 - 6 } & $\begin{array}{c}\text { Muco- } \\
\text { purulent }\end{array}$ & 3 & 2.7 & 4 & 3.6 \\
\cline { 2 - 6 } & Total & 111 & $100.0 \%$ & 111 & $100.0 \%$ \\
\hline
\end{tabular}

Table 3: Association of MTB positivity with sputum sample quality and consistency for both spot and morning.

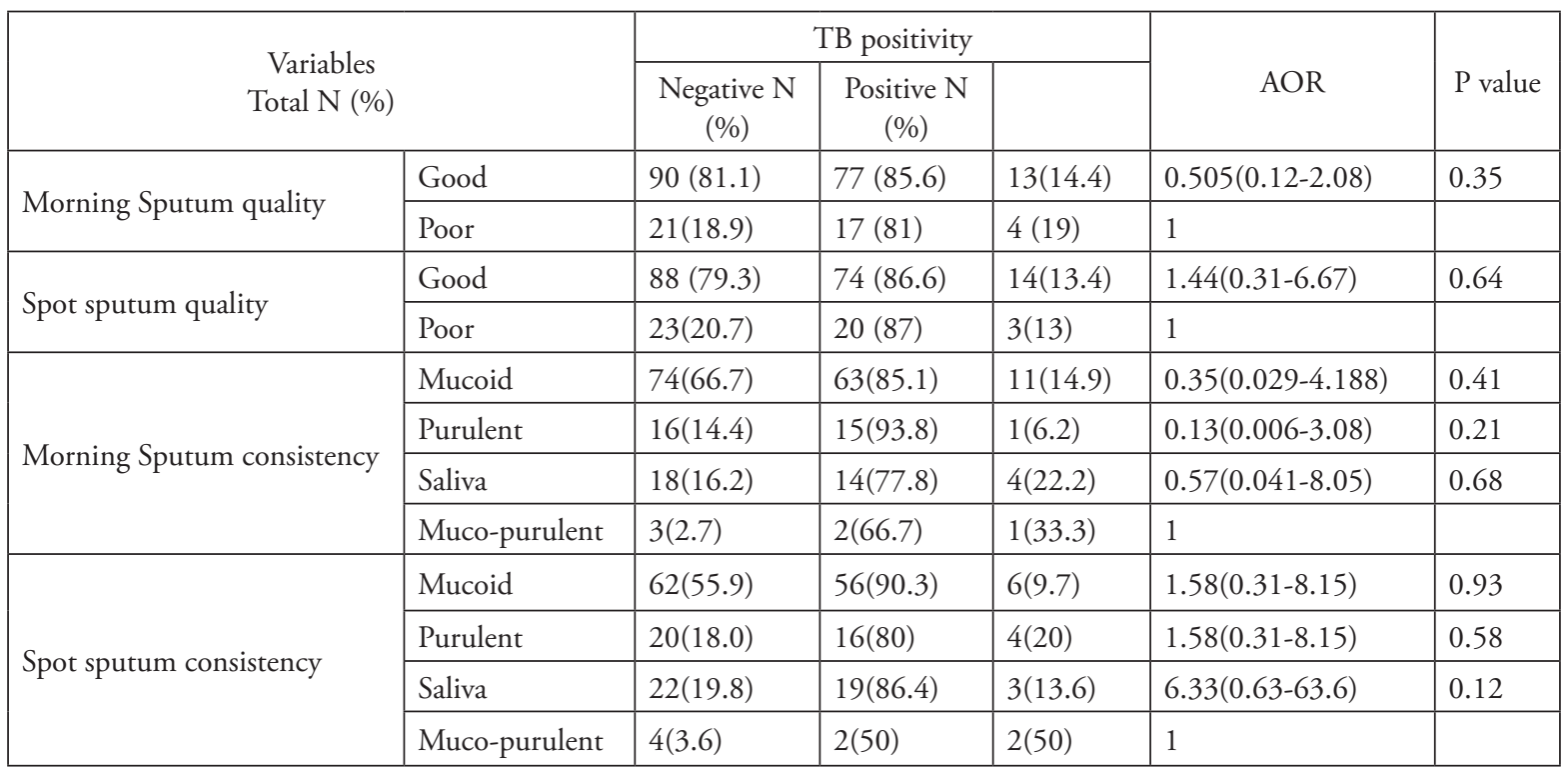

\section{Discussion}

In this study, the detection of the morning and spot sputum samples were assesses using Gene Xpert MTB/RIF Assay. In this study, the yielding accuracy of spot and sputum samples were almost similar. This is almost similar to the study done by Tingyu Tang and his colleagues in china in 2017G.C (Tingyu \& Fang, 2017).

The study conducted in Uganda in 2017G.C by Amanda $\mathrm{J}$ and his colleagues stated that, there was no significance difference in diagnosis result Gene Xpert testing between salivary and non salivary (good quality) specimens. This was also similar in this research, which shows no relation with quality and consistency for TB detection using Gene Xpert MTB/RIF Assay (Amanda et al., 2017).

Another study conducted in Uganda in 2017 by Michael E concluded that spot sample is as good as early morning sputum samples for TB diagnosis. This study also concluded that there is no yielding difference between spot and morning collection methods for diagnosis of TB using Gene Xpert MTB/RIF Assay (Michael et al., 2017). 
Among 111 suspected TB patients in this study, 15.3\% were positive and $84.7 \%$ were negative using morning sputum sample. At same time, using spot sputum samples $13.5 \%$ positive and $86.5 \%$ were negative. This shows both morning and spot samples have almost similar yielding accuracy using GeneXpert MTB/RIF Assay. It was similar to the study in Kenyan 2016G.C, Gene Xpert testing of spot specimens identified 48 (57.0\%) of 84 cases; whereas GeneXpert testing of morning specimens identified 50 (66.0\%) of 76 cases were observed (Joseph et al., 2016).

\section{Conclusion}

Based on results of this study, yielding accuracy of both morning sputum samples and spot sputum samples is almost similar using Gene Xpert MTB/RIF Assay for detection of MTB. Additionally, the value difference between morning and spot result besides the quality and consistency of samples is not significant.

\section{Competing Interests}

We, authors declare that we have no competing interests.

\section{Authors' Contributions}

Habtamu M. has contributed to the conception of the study question, designed the study, collected the data, analyzed the data, interpreted the data and drafted the manuscript.

\section{References}

Amanda, J., Meyer, B., Collins, A., William, W., Samuel, K., Achilles, K., et al., (2017). Sputum quality and diagnostic performance of Gene Xpert MTB/ RIF among smear negative adults with presumed tuberculosis in Uganda. Journal pone, 12(7), 1-12. https://doi.org/10.1371/journal.pone.0180572

Biruk, M., Yimam, B., Abrha, H., Biruk, S., \& Amdie, F., Z. (2016). Treatment outcome of tuberculosis and associated Factors in an Ethiopian university hospitals. Advances in Public Health, 2016, 1-9. https://doi.org/10.1155/2016/8504629

Charles, P., Davis, C., Gail, W., David, N., \& Milton, R. (2000). Baron's Medical Microbiology. $4^{\text {th }}$ edition.

Chemhuru, M., Duka, M., Nanan-n'zeth, K., J., B., Simons, S., Broucke, S., V., D., Fajardo, E. and Bygrave, H. (2013). MD $\delta 3$ Implementation of Xpert MTB/ REF Assay in Buhera District, Zimbabwe. DRTB guidelines: Zimbabwe; WHO. Retrieved from:

https://pdfs.semanticscholar.org/ec0a/76 f 8 fe $180 \mathrm{f} 7092$ be 0 a 1 e 8 f 102 fodd 3055 e 57 . pdf?_ga=2.2999730.32023939.1594883755842817547.1594883755

Daniel, D. (2014). Comparative performance between Xpert MTB/RIF assay, led fluorescence microscopy, and ZN light microscopy for detection of mycobacterium tuberculosis in sputum samples in Addis Ababa, Ethiopia.

Ethiopian Public Health Institute, the 2nd BSC Based EPHI's Strategic Management Plan, 2015/16 to 2019/20. Retrieved from: http://repository.iifphc.org/ bitstream/handle/123456789/131/EPHI_2nd_SPM. pdf?sequence $=1$ \&isAllowed $=y$

FMOH. (2014). Evaluating the National Tuberculosis Control Program Challenges and ways forward: Ministry of Health Addis Ababa, Ethiopia.

FMOH. (2012). Guidelines for clinical and programmatic management of TB, Leprosy and TB/HIV in Ethiopia. Ministry of Health, Addis Ababa, Ethiopia, $5^{\text {th }}$ edition.

FMOH. (2007). Implementation guideline for TB/HIV collaborative activities: Ministry of Health Addis Ababa, Ethiopia.

Jochei, A., Akolhatkar, T. (1982). Medical laboratory science theory and practice. New Delhi. Tata McGraw-Hill publishing company limited, $1^{\text {st }}$ edition.

Joseph, S., Cavanaugh, S., Surbhi, M., Susan, M., et al. (2016). Comparative Yield of Different Diagnostic Tests for Tuberculosis among People Living with HIV. United States Centers for Disease Control and Prevention, Atlanta, Georgia, United States of America, Kenya Medical Research Institute (KEMRI) Center for Global Health Research, Kisumu, Western Kenya, March 29, 1-15. https://doi.org/10.1371/journal.pone.0152364

Michael, E., Murphy, N., Patrick, P., Phillips, J., Carl, M., et al. (2017). Spot sputum samples are at least as good as early morning samples for identifying Mycobacterium tuberculosis. BMC Medicine, 15(192), 2-10. https://doi.org/10.1186/s12916-017-0947-9

Tingyu, T., Fang L. (2017). Evaluation of Gene Xpert MTB/RIF for detecting Mycobacterium tuberculosis in a hospital in China. Journal of international medical research, 45(2), 10-18. https://doi.org/10.1177/0300060517698618 


\section{旬 \\ CHITKARA}

\section{Journal of Multidisciplinary Research in Healthcare}

Chitkara University, Saraswati Kendra, SCO 160-161, Sector 9-C, Chandigarh, 160009, India

Volume 6, Issue 1

October 2019

ISSN 2393-8536

Copyright: [@ 2019 Habtamu Molla] This is an Open Access article published in Journal of Multidisciplinary Research in Healthcare (J. Multidiscip Res. Healthcare) by Chitkara University Publications. It is published with a Creative Commons Attribution- CC-BY 4.0 International License. This license permits unrestricted use, distribution, and reproduction in any medium, provided the original author and source are credited. 